\title{
Expectant management of intrauterine growth restriction pregnancy: perinatal outcome
}

\author{
Diana Andzane ${ }^{1 *}$, Anna Miskova ${ }^{1,2}$, Svetlana Polukarova $^{3}$, Igor Gapatins ${ }^{1}$
}

\author{
${ }^{1}$ Department of Obstetrics, Riga Maternity Hospital, Riga, Latvia \\ ${ }^{2}$ Department of Obstetrics \& Gynaecology \& Reproduction, Infertility Clinic iVF Riga, Riga, Latvia \\ ${ }^{3}$ Department of Neonatology, Children's Clinical University Hospital, Riga, Latvia
}

Received: 14 January 2015

Accepted: 16 February 2015

\section{*Correspondence: \\ Dr. Diana Andzane, \\ E-mail: andzane.diana@gmail.com}

Copyright: $\odot$ the author(s), publisher and licensee Medip Academy. This is an open-access article distributed under the terms of the Creative Commons Attribution Non-Commercial License, which permits unrestricted non-commercial use, distribution, and reproduction in any medium, provided the original work is properly cited.

\begin{abstract}
Background: Intrauterine growth restriction (IUGR) is the reason for increased morbidity and mortality in all periods of human life. The development of this pathology defines a variety of factors many of which are preventable. There is still no developed effective tactics for pregnancy and delivery, which would protect both mother and child from undesirable consequences.

Methods: The research was made in Riga Maternity hospital in Latvia. In the research were included 96 neonates with the weight below 10th percentile (IUGR group) as well there was compiled the control group. We evaluated the condition of neonate by 13 criteria and studied its frequency depending on the gestational period. The weight of neonates was estimated using the percentile scales - intrauterine growth curves based on U.S. data.

Results: In the subgroup of $37-39^{\text {th }}$ week in the IUGR group in comparison with $40-42^{\text {nd }}$ week subgroup, statistically more often was noticed hypoglycaemia, polycythaemia, acidosis, poor feeding, neurological abnormalities, transportation to an intensive care unit, transportation to another hospital for the further treatment and there was a higher number of days spent in the hospital. In the subgroup of $37-39^{\text {th }}$ week in the control group were just 2 criteria that were statistically more frequent.

Conclusions: Recognizing the IUGR to the fetus, there is justified the temporizing tactics with regard to resolution of pregnancy if only the health status of mother allows that and preeclampsia is excluded.
\end{abstract}

Keywords: Intrauterine growth restriction, Early neonatal period, Delivery management

\section{INTRODUCTION}

Traditionally, the optimal sizes of new-borns correspond to $10-90^{\text {th }}$ percentiles while the neonates, which are under this abutment, can be considered too small for their gestational age (small for gestational age - SGA). ${ }^{1,2}$

Antenatal can anticipate and prepare for the birth of small fetus, diagnosing the intrauterine growth restriction (IUGR) and differentiating it from the constitutionally small fetus.
IUGR refers to a condition in which the fetus is unable to achieve its genetically determined potential size. ${ }^{3-5}$ SGA includes both IUGR and fetuses that are constitutionally small for gestational age. ${ }^{1}$ The term SGA is recommended to use for children after the birth but the term IUGR should be used before the birth. ${ }^{6}$ The possibilities to differentiate constitutionally small fetus from IUGR is rather limited. ${ }^{4}$

IUGR clinically diagnoses if the weight of the fetus is below the 10th percentile of appropriate gestational time and gender, ${ }^{2,6}$ but this anomalous fetal growth should be 
determined in sequential measurements. ${ }^{3}$ IUGR is the reason for intrauterine death, perinatal death, premature birth, complicated postnatal period, increased morbidity and mortality in childhood (for example, sudden infant death syndrome), susceptibility to diseases in adulthood (infections, autoimmune diseases, impaired glucose tolerance, arterial hypertension, obesity). ${ }^{4,7,8}$ The aim of the research is to comprehend the influence of expectant management of IUGR pregnancy on the perinatal outcomes.

\section{METHODS}

\section{Trial design and participants}

During the retrospective research were examined data of patients in Riga Maternity hospital in Latvia for the year 2013. In the research were included 96 neonates with the weight below $10^{\text {th }}$ percentile (IUGR group). In the control group were included 98 neonates with the weight that corresponds to $11-89^{\text {th }}$ percentile. Both groups were divided into 2 subgroups:

1) Neonates who born at $37-39^{\text {th }}$ gestational week;

2) Neonates who born at $40-42^{\text {th }}$ gestational week.

\section{Outcomes}

The weight of neonates was estimated using the percentile scales - intrauterine growth curves based on U.S. data. We evaluated the condition of neonate by 13 criteria: hypothermia, hypoglycaemia, hypocalcaemia, polycythaemia, acidosis, poor feeding, neurological abnormalities, making infusions, perinatal hypoxia, respiratory distress syndrome, transportation to an intensive care unit, duration of hospital stay, transportation to another hospital for the further treatment. Hypothermia was defined as having a temperature level lower than $36.5^{\circ} \mathrm{C}$. Hypoglycaemia was defined as the detection of a glucose in blood serum in the birth day lower than $1.65 \mathrm{mmol} / \mathrm{l}$, in the first day after birth lower than $2.22 \mathrm{mmol} / \mathrm{l}$ or other days lower than $2.78 \mathrm{mmol} / \mathrm{l}$. Hypocalcemia was defined as having a serum total $\mathrm{Ca}$ concentration $<1.75 \quad \mathrm{mmol} / \mathrm{l}$. Polycythaemia was defined as the haematocrit $>70 \%$ or haemoglobin $>220 \mathrm{~g} / \mathrm{l}$. Acidosis was defined as having $\mathrm{pH}$ $<7.2$.

\section{Statistical methods}

The obtained data were statistically processed using MS Excel and SPSS programs. Statistical analysis of study data was performed by two-tailed $\mathrm{F}$ test. They were considered to be statistically believable if $\mathrm{P}<0.05$.

\section{RESULTS}

The peculiarities of early neonatal period are shown in Table 1. It was evaluated as long as the neonate stayed in Riga Maternity hospital.
There were compared each of the two subgroups within groups. Subgroups from different groups were not compared.

The weight of neonates in their birth moment among subgroups did not differ both in IUGR group and in the control group. At the check-out of the hospital it was a visible difference in the IUGR group where in the 40-42 week of pregnancy the weight was higher than it was in $37-39^{\text {th }}$ week of pregnancy. In the control group, this tendency was not observed. The weight loss in the third day statistically did not differ in any group. Here in the control group was the same tendency.

There were selected 13 criteria for a further comparison of groups. Comparisons of the results are summarized in the Table 1 . In the subgroup of $37-39^{\text {th }}$ week in the IUGR group in comparison with $40-42^{\text {nd }}$ week subgroup, statistically more often was noticed hypoglycaemia, polycythaemia, acidosis, poor feeding, neurological abnormalities, transportation to an intensive care unit, transportation to another hospital for the further treatment and there was a higher number of days spent in the hospital. In the subgroup of $40-42^{\text {nd }}$ week, none of the criteria was frequent. In the subgroup of $37-39^{\text {th }}$ week in the control group statistically more often was noticed making infusions and there was a longer time spent in the hospital but rarely came across with polycythaemia. Summarizing all the criteria, in the subgroup of $37-39^{\text {th }}$ week in the IUGR group 8 from 13 criteria were more frequent than in the subgroup of $40-42^{\text {nd }}$ week but in the subgroup of $37-39^{\text {th }}$ week in the control group were just 2 criteria that were statistically more frequent and one rare.

To exclude the heterogeneity of the groups, there were analysed birth characteristics, evaluated other possible factors that could cause already mentioned health problems as well as there were looked for possible reasons for faster resolution of pregnancy.

In the subgroups of the IUGR group were encountered statistically similarly both spontaneous and induced birth, both acute and planned caesarean. In the control group was also the same. In the subgroups of both IUGR groups equally often as a reason for faster resolution of pregnancy was mentioned acute fetal distress, changes in cardiotocography (CTG), changes in biophysical profile (BPP). In the subgroup of $40-42^{\text {nd }}$ week in the control group statistically more often was mentioned acute fetal distress, changes in CTG and other reasons unrelated to the fetus.

In the subgroup of $37-39^{\text {th }}$ week in the IUGR group statistically more often was preeclampsia $(5.7 \%$ vs. $1.7 \%$, $\mathrm{P}<0.0001)$, hemodynamic disorders $(17.1 \%$ vs. $4.9 \%, \mathrm{P}$ $<0.0001$ ), and other placental pathology (placental infarction, haemorrhage, villitis) $(22.9 \%$ vs. $6.7 \%, \mathrm{P}=$ 0.0003 ), but they were not the reasons for faster resolution of pregnancy. 
Table 1: Perinatal outcomes.

\begin{tabular}{|c|c|c|c|c|c|c|c|c|c|c|c|c|c|c|c|c|}
\hline $\begin{array}{l}\text { 을 } \\
\frac{0}{0} \\
\frac{0}{E} \\
\frac{1}{7}\end{array}$ & 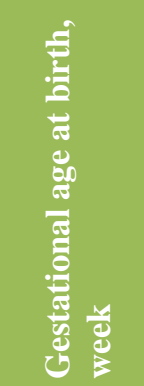 & 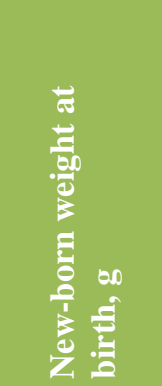 & 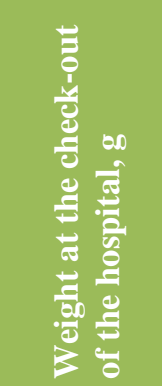 & 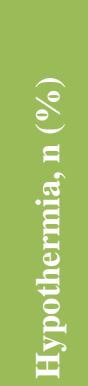 & 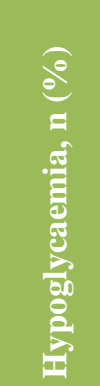 & 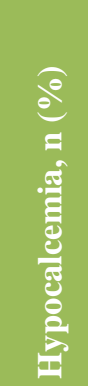 & 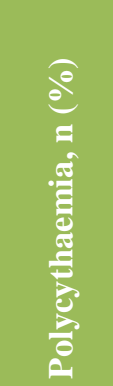 & $\begin{array}{l}\text { e } \\
= \\
0 \\
\frac{0}{0} \\
\frac{0}{8}\end{array}$ & 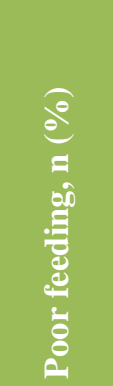 & 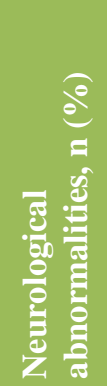 & 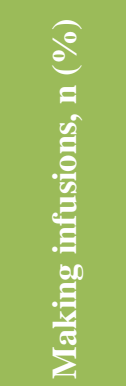 & 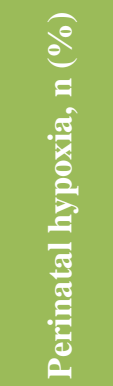 & 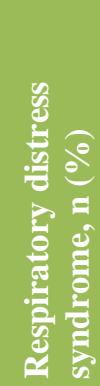 & 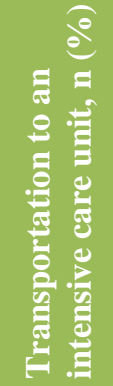 & 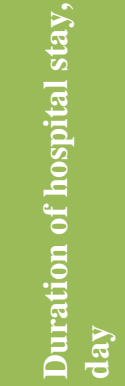 & 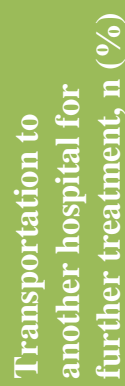 \\
\hline \multicolumn{17}{|l|}{ IUGR group } \\
\hline $\begin{array}{l}37-39^{\text {th }} \text { week } \\
\text { of pregnancy } \\
(n=35)\end{array}$ & $38.3 \pm 0.8$ & $2316 \pm 294$ & $2360 \pm 312$ & $\begin{array}{l}1 \\
(2.9)\end{array}$ & $\begin{array}{l}10 \\
(28.6)\end{array}$ & $\begin{array}{l}1 \\
(2.9)\end{array}$ & $\begin{array}{l}5 \\
(14.3)\end{array}$ & $\begin{array}{l}3 \\
(8.6)\end{array}$ & $\begin{array}{l}6 \\
(17.1)\end{array}$ & $\begin{array}{l}10 \\
(28.6)\end{array}$ & $\begin{array}{l}18 \\
(51.4)\end{array}$ & $\begin{array}{l}9 \\
(25.7)\end{array}$ & $\begin{array}{l}3 \\
(8.6)\end{array}$ & $\begin{array}{l}8 \\
(22.9)\end{array}$ & $5.6 \pm 2$ & $\begin{array}{l}8 \\
(22.9)\end{array}$ \\
\hline $\begin{array}{l}40-42^{\text {nd }} \text { week } \\
\text { of pregnancy } \\
(n=61)\end{array}$ & $40.3 \pm 0.5$ & $2756 \pm 268$ & $2721 \pm 211$ & $\begin{array}{l}1 \\
(1.6)\end{array}$ & $\begin{array}{l}6 \\
(9.8)\end{array}$ & 0 & $\begin{array}{l}4 \\
(6.6)\end{array}$ & $\begin{array}{l}2 \\
(3.3)\end{array}$ & $\begin{array}{l}5 \\
(8.2)\end{array}$ & $\begin{array}{l}8 \\
(13.1)\end{array}$ & $\begin{array}{l}16 \\
(26.2)\end{array}$ & $\begin{array}{l}8 \\
(13.1)\end{array}$ & $\begin{array}{l}4 \\
(6.6)\end{array}$ & $\begin{array}{l}6 \\
(9.8)\end{array}$ & $4.4 \pm 1.3$ & $5(8.2)$ \\
\hline P value & 0.01 & 0.53 & 0.01 & 0.06 & 0.004 & & 0.02 & 0.002 & 0.03 & 0.04 & 0.36 & 0.07 & 0.38 & 0.02 & 0.01 & 0.003 \\
\hline \multicolumn{17}{|c|}{ Control group } \\
\hline $\begin{array}{l}37-39^{\text {th }} \text { week } \\
\text { of pregnancy } \\
(n=53)\end{array}$ & $38.3 \pm 0.7$ & $3171 \pm 327$ & $2980 \pm 288$ & 0 & 0 & 0 & $\begin{array}{l}1 \\
(1.9)\end{array}$ & 0 & $\begin{array}{l}2 \\
(3.8)\end{array}$ & 0 & $4(7.5)$ & 0 & $\begin{array}{l}1 \\
(1.9)\end{array}$ & $\begin{array}{l}1 \\
(1.9)\end{array}$ & $4.1 \pm 1$ & $2(3.8)$ \\
\hline $\begin{array}{l}40-41^{\text {nd }} \text { week } \\
\text { of pregnancy } \\
(n=45)\end{array}$ & $40.3 \pm 0.5$ & $3443 \pm 272$ & $3263 \pm 273$ & 0 & 0 & 0 & $\begin{array}{l}2 \\
(4.4)\end{array}$ & 0 & $\begin{array}{l}1 \\
(2.2)\end{array}$ & $\begin{array}{l}3 \\
(6.7)\end{array}$ & $1(2.2)$ & 0 & 0 & 0 & $3.6 \pm 0.8$ & 0 \\
\hline$P$ value & 0.004 & 0.21 & 0.73 & & & & 0.004 & & 0.085 & & 0.0001 & & & & 0.04 & \\
\hline
\end{tabular}




\section{DISCUSSION}

In early neonatal period, the neonates with IUGR more often have various complications than neonates with a normal weight, including perinatal asphyxia and poorly controlled conditions of metabolism (hypoglycaemia, hypothermia, acidosis, hypocalcemia, polycythaemia, coagulation disorders). In case if the foetuses born prematurely, more frequently there appear illnesses that are connected with prematurity (respiratory distress syndrome, necrotizing enterocolitis) than it happens with healthy prematurely born child. ${ }^{8,9}$ It is considered that SGA neonates during the first month are able to grow and gain strength faster. ${ }^{10}$ Our research adds that SGA neonates who are born in 40-42 ${ }^{\text {nd }}$ week of pregnancy gain weight faster than neonates born in $37-39^{\text {th }}$ week of pregnancy.

We evaluated the condition of neonate by 13 criteria, which are more common for SGA neonates and studied its frequency depending on the gestational period. From the results, it can be concluded that even for the full-term pregnancy there are less complications if neonate is born in the $40^{\text {th }}$ week of pregnancy or later. However extending the pregnancy, preeclampsia should be excluded because it was more common in the subgroup of $37-39^{\text {th }}$ week of pregnancy and theoretically, it could affect unsatisfactory state of health of the neonate. Europe - wide research TRUFFLE shows that maternal hypertensive conditions are closely related to a faster resolution of pregnancy and negatively affects the neonatal outcome of neonate. ${ }^{11}$ From the 90 s of this century gradually increases the number of caesareans because theoretically the latest technologies will be able to provide more favourable environment for the neonates. ${ }^{10}$ Our results show that choosing the right tactics for the pregnancy with IUGR, preference is given to temporizing tactics and further vaginal delivery but there is no reason for the faster resolution of pregnancy, if only the health status of mother allows that and preeclampsia is excluded. Another large research DIGITAT revealed that there are no significant differences between temporizing tactics and induction of labour with suspicions of IUGR both in mother and child outcomes. That is why both tactics are acceptable. ${ }^{12}$

Funding: No funding sources

Conflict of interest: None declared

Ethical approval: The study was approved by the Riga Stradins University ethics committee

\section{REFERENCES}

1. Gardosi J. Normal fetal growth. In: Edmonds DK, eds. Dewhurst's Textbook of Obstetrics \& Gynaecology. 7th ed. Oxford, UK: Blackwell Publishing; 2007: 28-33.
2. Fabre E, González de Agüero R, de Agustín JL, Ezquerra A. Intrauterine growth restriction: concept and epidemiology. In: Kurjak A, Chervenak FA, eds. Textbook of Perinatal Medicine. 2nd ed. London, UK: Informa; 2006: 1238-1246.

3. Stanisic Chou T, Toohey JS. Fetal growth disorders. In: Di Saia PJ, Chaudhuri G, Giudice LC, Moore TR, Porto M, Smith LH, eds. Women's Health Review: A Clinical Update in Obstetrics-Gynecology. Philadelphia, PA: Elsevier Saunders; 2012: 97-100.

4. Albu AR, Anca AF, Horhoianu VV, Horhoianu IA. Predictive factors for intrauterine growth restriction. J Med Life. 2014;7(2):165-71.

5. Harkness UF, Mari G. Diagnosis and management of intrauterine growth restriction. Clin Perinatol. 2004;31:743-64.

6. Ernst SA, Reeske A, Spallek J, Petersen K, Brand T, Zeeb H. Care-related factors associated with antepartal diagnosis of intrauterine growth restriction: a case-control study. BMC Pregn Childbirth. 2014;14(1):371.

7. Smith GCS, Lees CC. Disorders of fetal growth and assessment of fetal well-being. In: Edmonds DK, eds. Dewhurst's Textbook of Obstetrics \& Gynaecology. 7th ed. Oxford, UK: Blackwell Publishing; 2007: 159-165.

8. Baraibar R, Sánchez L. Growth-restricted newborns: characteristics and management. In: Kurjak A, Chervenak FA, eds. Textbook of Perinatal Medicine. 2nd ed. London, UK: Informa; 2006: 1313-1325.

9. Gonzalez JM, Stamilio DM, Ural S, Macones GA, Odibo AO. Relationship between abnormal fetal testing and adverse perinatal outcomes in intrauterine growth restriction. Am J Obstet Gynecol. 2007;196(5):e48-51.

10. Carrera JM, Figueras F, Devesa R, Mallafré J. Management of small-for-gestational-age fetuses: antenatal and intrapartum strategies. In: Kurjak A, Chervenak FA, eds. Textbook of Perinatal Medicine. 2nd ed. London, UK: Informa; 2006: 1296-1312.

11. Lees C, Marlow N, Arabin B, Bilardo CM, Brezinka C, Derks JB, et al. Perinatal morbidity and mortality in early-onset fetal growth restriction: cohort outcomes of the trial of randomized umbilical and fetal flow in Europe (TRUFFLE). Ultrasound Obstet Gynecol. 2013;42:400-8.

12. Boers KE, Vijgen SMC, Bijlenga D, van der Post JAM, Bekedam DJ, Kwee A, et al. Induction versus expectant monitoring for intrauterine growth restriction at term: randomized equivalence trial (DIGITAT). BMJ. 2010;341:c7087.

DOI: $10.5455 / 2320-1770$. ijrcog20150405

Cite this article as: Andzane D, Miskova A, Polukarova S, Gapatins I. Expectant management of intrauterine growth restriction pregnancy: perinatal outcome. Int J Reprod Contracept Obstet Gynecol $2015 ; 4: 312-5$ 